\title{
Violence in the Lives of Rural, Southern, and Poor White Women
}

\section{Naomi Farber' and Julie E. Miller-Cribbs ${ }^{2}$}

\begin{abstract}
Poor White single mothers and their children in non-urban communities in the American South experience high levels of domestic violence. We report selected findings from a life history study among White, low-income, unmarried mothers in South Carolina. Here, we examine how domestic violence in both childhood and adulthood may inhibit asset development by diminishing low-income single mothers' accumulation of human and social capital, thus compromising their well-being as adults and parents.
\end{abstract}

\section{Keywords}

domestic violence, southern poverty, White women

\section{Introduction}

As the major reforms in public welfare were enacted in 1996 in the United States, there has been considerable research examining the impact of various changes in program requirements, in particular time limits for benefits and the increased expectation that women with children be employed. This growing body of scholarship concerning women in poverty has continued, to a large extent, the traditional focus on low-income, especially minority, residents of urban communities. Considerably less attention has been paid to poor women in the rural South, especially single mothers and their children (Myers \& Gill, 2004; Scott, London, \& Myers, 2002). There is evidence, however, that very poor single mothers in the non-urban South, like their urban and northern counterparts, are at high risk of domestic violence and its negative consequences for their overall well-being, including their economic status. The convergence

\footnotetext{
'University of South Carolina, Columbia, USA

2University of Oklahoma,USA

Corresponding Author:

Naomi Farber, College of Social Work, University of South Carolina, Columbia, SC 29208, USA.

Email: Naomi.farber@sc.edu
} 
of poverty, single motherhood, and domestic violence has profound significance not only for women who may be victims but also for their children who face multiple challenges to optimal development. Drawing on the work of Sherraden (1991), we examine how domestic violence in both childhood and adulthood may inhibit asset development by diminishing a single mother's accumulation of human and social capital, thus compromising her well-being as adult and parent.

In the context of limited empirical and theoretical literature examining poverty in the South, the overarching objective of this study was to examine whether extant literature adequately described and explained the high incidence of childbearing outside of marriage among poor White Southern women. Using a fundamentally inductive approach, the exploratory descriptive study was designed to identify major concepts emerging from the women's own perspectives on salient experiences contributing to their current economically, socially, and often medically disadvantaged status as single mothers. These perceptions were elicited through focused life history interviews that incorporated both the women's descriptions of significant events and circumstances within general domains known from other research to increase risk of adverse adult outcomes and also emergent themes that the women identified as significant.

\section{Background}

\section{Southern Rural Context}

Continuing historic patterns of disadvantage, family and child poverty are more prevalent in the South than any other region of the United States (Nord, 1999). Rates of child poverty are especially high in non-metropolitan areas, $24.9 \%$ in the South in comparison with 20.3\% nationally (Southern Rural Development Center, 2003). The reasons for persistent poverty in the South are complex, emerging from a tradition of low public investment in basic education and technical training that results in a poorly trained workforce unable to attract high-paying sources of employment. In recent years, the greatest growth job opportunities have occurred in the low-skill service sector with low wages and poor benefits, the hallmark of working poverty.

While African Americans suffer the highest rates of poverty among Southerners, Whites are more likely to be poor in the South than elsewhere in the nation. In particular, unmarried Southern women and their children are at very high risk of poverty. Recent data show that in both the rural and urban South, children who reside in motheronly families experience poverty at significantly higher rates than those children in two-parent families (Southern Rural Development Center, 2003).

Rising rates of childbearing outside of marriage and of divorce have contributed to South Carolina ranking third nationwide in the proportion of families headed by single women (Annie E. Casey Foundation, 2009). In 2006, more than 30\% of births to White women were outside of marriage and, in $2007,23 \%$ of all White children in the state lived in a single-parent family. Although recent research reveals variability and complexity in both family structure and function not evident in the category of "singlemother family," the fact remains that unmarried mothers with low levels of education 
are unambiguously at risk of poverty and its attending challenges (England \& Edin, 2007; Osborne, 2002; Teitler \& Reichman, 2001).

An important source of disadvantage among single mothers in South Carolina, as elsewhere, results from relatively low levels of educational attainment. In 2006, 22\% of all White first-time mothers had less than a high school diploma, and rates are even higher among unmarried mothers. Education, a primary form of human capital, is critical for individuals seeking higher wage employment and opportunities in both urban and rural areas (Findeis, 1995; Findeis \& Jensen, 1998). Yet, educational attainment and other forms of human capital remain lower in rural than in urban areas.(Rural Poverty Research Institute, 1999).For example, of rural parents who received welfare in 1996, more than one third did not graduate from high school (Cook \& Dagata, 1997) and even fewer rural individuals obtain higher education or college degrees.

\section{Violence Against Women and Children}

The health and well-being of poor women and children are also threatened by high rates of domestic violence in South Carolina. Despite recent legislative attempts to strengthen enforcement of legal protections for victims of domestic violence, South Carolina continues to fall behind other states in public funding earmarked for health care and domestic violence, has not enacted fatality review teams in domestic violence homicides, and does not require domestic violence health care protocols or screening requirements for health care providers and facilities, (Durborow et al, 2013). Reflecting the seriousness of the problem, South Carolina has been ranked as high as 1 st in or has been in the top 10 in the nation in number of homicides by domestic violence in the past 10 years (McManus, 2006; Violence Policy Center, 2013; Saunders-Medlock, 2003). (). Over the last 12 years, an average of 33 women in South Carolina have been killed each year as a result of intimate partner violence (South Carolina Coalition Against Domestic Violence ans Sexual Assualt, n.d.). The cost of domestic violence is borne by victims, their children, and the larger society. Consistent evidence finds that women who experience domestic violence as adults, and children who are victims or witness domestic violence, are at risk for a range of physical and mental health problems, costing more than US $\$ 8.23$ billion annually for medical and mental health services and lost productivity from paid work and household chores (Arias, 2004; Eby, 2004; Riger \& Staggs, 2004; L. Vogel \& Marshall, 2001).

Despite some inconsistency among findings, the weight of research suggests a complex relationship between domestic abuse and compromised employment history and earnings and welfare recidivism (Riger \& Staggs, 2004; Scott et al., 2002). Several studies have found that the physical and mental health problems associated with experiencing domestic violence result in reduced and unstable employment and lower earnings among low-income women (Danziger, Kalil, \& Anderson, 2000; Kimerling et al., 2009; Riger \& Staggs, 2004; Smith, 2001; Tolman \& Rosen, 2001). As low-income women are more likely than other women to experience abuse, the potential consequences of domestic violence for women whose economic stability may already be tenuous are especially significant (FVPF, 2001; Schechter, 2000; Straus \& Gelles, 1990; L. Vogel \& Marshall, 2001). 
In addition to the less direct impact of health and mental health problems on women's employment stability, male perpetrators of abuse make it difficult for their female partners to work. Common behaviors include harassment both off and on the job, interference with attempts to attain education or training, and inflicting injuries that cause women to miss work or perform poorly at their jobs (FVPF, 2001; Raphael \& Tolman, 1997; Scott et al., 2002). Not surprisingly, then, in large part due to their economic instability, victims of both past and current abuse are over-represented among welfare recipients (Raphael \& Tolman, 1997).

In homes where domestic abuse occurs, children's immediate and long-term wellbeing can be harmed whether they witness or are the direct victims of violence. The developmental significance of this impact is highlighted by recent research examining how adverse childhood experiences (ACEs) such as exposure to domestic violence may negatively affect neurobiological functioning with problematic behavioral expression (Anda et al., 2006). Anda et al. (2006) found that "the risk of every outcome in the affective, social substance abuse, memory, sexual, and aggression-related domains" rose with increased scores or ACEs, suggesting a cumulative or "cascade" effect of exposure to severe environmental stressors over the life course (p. 174). This is consistent with other evidence of negative consequences of either witnessing or being the victim of domestic abuse, including emotional and behavioral problems, cognitive difficulties, substance abuse, posttraumatic stress disorder (PTSD), and other traumarelated symptoms that may appear over the life course (Arias, 2004; Carlson, 1984; Edelson, 1999; Spaccarelli, Caotsworth, \& Bowden, 1995). Children in the presence of domestic violence are much more likely to experience physical abuse themselves perhaps 15 times more likely (American Psychological Association, 1996; Edelson, 1999; Peled, Jaffe, \& Edelson, 1995; Stacy \& Shupe, 1993; Straus \& Gelles, 1990; Child Welfare Information Gateway, 2013).). The developmental risks and long-term consequences of childhood maltreatment are evident in research finding that male abusers often witnessed violence in their own childhood (Hotaling \& Sugarman, 1986; Mihalic \& Elliott, 1997; Romans, Poore, \& Martin, 2000).

Certain characteristics of rural life magnify the causal conditions of and consequences associated with domestic violence, including the unavailability of transportation, child care, and shelters; isolation, both geographic and social; higher incidence of weapons in the household; lack of health insurance and health care services; and limited social services, job opportunities and training. These factors can all contribute to the difficulties many rural women face in their attempts to leave violent and abusive relationships (Chamberlain, 2002; Johnson, 2000; W. Vogel \& Coward, 1995).

\section{Substance Abuse, Poverty, and Family Violence}

Inextricably interwoven with these patterns of domestic violence and poverty among single mothers is the presence of substance abuse, both in the perpetration of violence and in the concurrent and consequential use of substances by victims and witnesses of the violence. Many male perpetrators of domestic violence experienced abuse as children - about $23 \%$ in South Carolina - and in adulthood frequently suffer from various 
mental health problems, including alcohol and substance abuse (Gortner, Gollan, \& Jacobson, 1997; Kendler, 2002; Romans et al., 2000). In South Carolina, more than one quarter of reported incidents of domestic violence involved the use of alcohol and $9 \%$ the use of illicit drugs by the perpetrator (Bradbury \& McManus, 2007).

Frequently, women who suffer from domestic violence attempt to cope either by initiating or increasing their use of substances (Curcio, 1997; Office for the Prevention of Domestic Violence, 1998; Scott et al., 2002). Welfare recipients who were either past or current victims of domestic violence have been found to have higher rates of both substance abuse and mental health problems (Browne, Salomon, \& Bassuk, 1999; Lyon, 2000; Tolman \& Rosen, 2001). It is clear that there is an extremely complex interactive relationship among factors contributing to women's economic, social, emotional, and physical health in the context of current and childhood poverty, domestic violence, and other severe family dysfunction. This study examines the convergence of these factors from childhood through adolescence to adulthood in contributing to White single mothers' poverty in the Southeast.

\section{Conceptual Framework of the Research}

Scholars of economic disadvantage employ different definitions of assets, social capital, and human capital. For purposes of this analysis, assets are defined as the economic resources such as home ownership or savings accounts that are "typically viewed as a storehouse for future consumption" (Yadama \& Sherraden, 1996, p. 3). Human capital includes the capacities — innate, derived, or accumulated - in individuals that enable them to participate productively in society, such as level of education, job skills, intelligence, or personality. Social capital refers to social relationships that exist both within and outside of the family, specifically, "the set of resources that inhere in family relations . . that are useful for the cognitive or social development of a child or young person" (Coleman, 1990, p. 300). Social capital, for example, exists in the relationships among viable social and kin networks that can lead to the development of human capital and asset development.

This article focuses specifically on selected data from a comprehensive life history study, examining domestic violence as a strong theme over the life course of poor, White, single mothers in the South. We examine how human and social capital become compromised by domestic abuse over time, thus resulting in women who are asset poor and who face limited opportunities for economic stability through employment or marriage free of domestic violence.

\section{Method}

\section{Sampling}

The sample included 32 women who met the following criteria: age 18 or older, White (self-identified), not currently married or living steadily with a romantic partner, had at least one child, had a very low income, and had attained no educational credentials 
beyond a high school diploma or general educational diploma (GED). Participation was solicited in and near two small cities in South Carolina through two methods. First, fliers describing the study, including all of the sample inclusion criteria listed above, were placed in waiting areas in the two county departments of social services and their welfare-to-work programs. While the flier did not define a threshold for "very low income," we assumed, for the purposes of the initial screening, that women seeking or participating in the income maintenance-related services at the Department of Social Services would likely qualify for Temporary Assistance to Needy Families (TANF) and thus by definition have a "very low income." All of the women who called agreed to participate and all met the sample inclusion criteria. The second method of recruitment was through snowball sampling. At the end of each interview, we asked the respondent to suggest other women who might be interested in participating in the study.

It is likely that most of the women, many of whom had no steady source of income at all, participated primarily to earn the US $\$ 25$ that was paid for each interview. This motivation was apparent among several women who agreed to participate contingent upon scheduling the interview, hence receiving payment, within a specified short time, often at the end of the month when cash tended to be scarce. Thus, the financial urgency among these women may represent a sample bias. In addition, using snowball sampling resulted in a few small clusters of respondents within the larger sample who were members of a social and/or kin network. While the majority of respondents knew only one other potential participant, this feature of the sample, the common deep financial need, and the geographical focus on two areas within one state limit generalizability of the findings. In addition, although the explicit purpose of the study and its methodology rested on eliciting women's own perceptions, the nature of retrospective and self-reported data constitutes potential limitations.

\section{Data Collection}

Data were collected by four researchers-the two authors and two social work doctoral students who had significant experience in clinical practice. Nearly all interviews took place in the participant's home or current residence (e.g., the home of a relative or friend) at the discretion of the participant.

Data consisted of focused life histories gathered through face-to-face interviews. The interviews included primarily open-ended questions with active use of probes for detail and clarification. Aside from questions about selected demographic characteristics, the only exception was a series of survey questions regarding family and social relations and material well-being used as a comparison to a companion study of kin networks among rural African American women. The interview guide provided a set of topics that reflected substantive domains. They included detailed historical and current information about demographic characteristics; number and ages of children; subsistence strategies, including sources of income; housing, including residential movement and physical conditions of current housing; family of origin; educational and occupational experiences and aspirations; marriage and other relationships with 
men; pregnancy and motherhood; and hopes for the future of their children and themselves. These categories were chosen to reveal current experiences in fundamental aspects of the women's lives, while examining past critical junctures-events and decisions - that current literature assumes are influences on later well-being, including accumulated assets and capital.

Building on the inherent strengths of qualitative methods in examining individual experience, two major changes were made in the structure and content of the interviews over the course of the study. First, the interviewers became more flexible in guiding the order of topics discussed to accommodate the way each participant seemed to view her past and present. Second, as themes emerged consistently in early interviews, these themes were probed more fully in subsequent interviews. Similar to Bell's (2003) account of the emergence of domestic violence in the "Three City Study," the recurrent history of domestic violence from childhood through adulthood was an emergent theme revealed in the very first interview and included thereafter. All interviews except one, during which notes were taken (as a result of a technical failure), were audiotaped and transcribed verbatim.

\section{Data Analysis}

The interview data were analyzed in two ways: thematically across interviews and from a developmental perspective through constructing a chronological time line of major events for each participant. The qualitative software program ATLAS -ti was used for thematic analysis. The analytic themes were based on categories that were pre-determined and constituted interview topics, and also new themes that emerged from the life histories themselves, such as childhood and adult domestic violence.

\section{Findings}

\section{Sample Characteristics}

The age of the 32 participants ranged from 18 to 46 . The mean age was 30 , but the majority of the women were in their $20 \mathrm{~s}$. Well over half of the women, $62 \%$, had never been married and the rest were divorced or separated from their husbands; one woman married at age 15, but obtained an annulment when she discovered that her "husband" was married. Most of the women had one or two children; one had five (by age 21) and another had four children. Among those women with more than one child, $78 \%$ had children with different biological fathers. The earliest maternal age at first birth was 13 and the oldest 31; the average age was 19. The average level of formal education attained was less than 12 th grade.

By definition of eligibility for inclusion in the sample, all of the women were poor in terms of income and other financial assets. Most of the respondents were not living in their "own home" because they could not afford either rent or the deposits necessary to rent most trailers or apartments. Only one woman, the sole participant receiving child support consistently, owned her own home. 
The participants qualified for TANF at the time of the interview (though almost none knew that TANF had replaced Aid to Families With Dependent Children [AFDC]). Eighteen women received some combination of Medicaid for their children, child care ("ABC") vouchers, and/or food stamps, but only a few received cash assistance. Typically, their sources of cash income were so unpredictable and unreliable that few were able to calculate their annual or even monthly income; among those who could provide specific information, the average was about US\$8,000 per year, less than the federal poverty line in 2004 for a single individual and about half the poverty line for a family of three. Some women reported having no reliable source of income each month.

All of the women had a history of sporadic, low-wage employment, most starting when they were adolescents. A few had engaged in prostitution or other illicit means of generating income, such as selling drugs. At the time of the interview, roughly $30 \%$ of the participants were working some hours in minimum-wage, low-skill jobs and most others were seeking employment. Their jobs included working as waitresses; working in fast-food restaurants, convenience stores, or nursing homes; cleaning houses; and the unusual occupation of delivering doves for funerals. A few women babysat for friends or family - women who themselves worked in low-wage jobs and relied on participants' help to keep their marginal employment. Consistent with other families living in poverty in rural areas, lack of reliable transportation was cited as a major and chronic source of difficulty in finding and maintaining employment (Economic Research Service, U.S. Department of Agriculture, 1998).

\section{Childhood Domestic Abuse}

More than three quarters of the women describe families of origin characterized by some combination of physical and emotional violence between their parents, and physical and/or sexual abuse of themselves during childhood. Family violence usually occurred against a backdrop of chronic alcohol and/or drug abuse by one or both of their parents. Thus, many of the women were both witnesses to and direct victims of domestic violence as well as being the children of substance abusers.

\section{Parental Domestic Violence and Substance Abuse}

The majority of the women reported that their mothers were victims of domestic violence at the hands of their husbands and/or boyfriends. Although the particular details of their experiences varied, the women's descriptions contained characteristic themes. Descriptions of their home environment revealed acute awareness of the violence between their parents or stepparents:

Horrible. My dad was an alcoholic and he was very abusive to my mom. He was physically - he never hurt any of us, and we never seen it, but he was very physical. 
Terrible. My father was very abusive to my mother. Hittin' . . . a lot of yelling, up all night almost every night. We never got a full night's sleep to go to school on because it was always wake up. We were always brought into the show.

Both (parents) drank . . . I remember in Louisiana he'd get drunk and he was very violent and mean to everybody. My stepmother used to tell us, she'd hear the truck coming and she'd say to go get into the bed now. And he would wake us up each time they'd get into it. He was very mean. He would scare me.

Um, well, my mom took a lot of crap from my dad. They always fought . . my dad is a drinker.

Several women's fathers were unable to work and their only income was from disability benefits. However, as is common with very abusive men, they limited their wives' activities, including their ability to supplement the family income through work. Thus, family poverty was often exacerbated by domestic abuse:

My dad is not much to talk about. He was an abuser. And he was an alcoholic and he did drugs ... My mother wasn't allowed to work when we were growing up because my dad was so abusive. He would beat her. So she didn't work. She stayed home. He would control everything she did.

\section{Child Physical and Sexual Abuse}

About one-half of participants reported being victims themselves of physical and/or sexual abuse as children. One participant's mother left her family after her abusive husband allegedly attempted to poison her. He then turned to his daughter:

... I think she came back just for a very short while, a couple of weeks, and then ... she literally left with just the clothes on her back and didn't say nothing. She didn't take us or anything ... when she moved out that's when he started abusing me ... Since she wasn't there anymore, he took it out on me.

Another woman's father beat her, though never in front of anyone:

It was always after I'd come home from school. I never knew if I was coming home to a Jekyll and a Mr. Hyde.

One woman describes her substance-abusing parents as "trash," who burned her with scalding water and engaged in other forms of severe physical abuse. At the age of 1, she was taken into custody by the Department of Social Services after having been abandoned for several days in a trailer. Unfortunately, her maternal grandparents adopted her but provided a harsh and unloving home, which she left in early adolescence.

Several women were sexually abused by family members. In one instance, the participant's mother's drug use prevented her from protecting her daughter from abuse. 
Although the woman described a strong emotional bond with her mother, her mother's own functional impairment contributed to an early life of emotional and economic instability and risk:

My momma was a heroin addict and I didn't have a lot of things kids had. You know, I couldn't have kids over and stuff. My mom did the best she could for who she was. Which was an addict ... I was molested from 9-13 . . my uncle. It's life. He was sick. A sick person I don't hate him. I love him ... He's just a sick person.

\section{Marital Dissolution}

Most participants' parents who were married subsequently divorced or separated over the course of their own childhood; other mothers who never married typically had serial live-in partners. Several participants explicitly link domestic abuse to their parents' divorce or separation:

... they separated when I was like 2 or 3 , and he was a really bad alcoholic and wouldn't hold a job at all ... he was real violent. He used to beat her up a lot.

I was 13 when their divorce was final. My dad was abusive to my mother-all of it (physical, emotional, verbal). He drank a lot.

The participant whose mother, a heroin addict who experienced several abusive non-marital relationships, never lived in a stable family, nor in one place very long:

I remember days coming to pick me up on the motorcycle from school. "Come on, baby, it's time to go." We'd just leave. Go to another state. And start all over again ...

Many women made explicit reference to the economic impact of parental separation in the context of domestic abuse:

He [father] came around every once in a while, but my mom would always fight him off because he didn't pay child support and he never gave us any money ... I think he meant well, like he would write us and say, "I'm going to send you this, I'm going to send you some school clothes," but he never would.

Another young woman became solely responsible for her younger sister after their mother left her husband and two adolescent daughters:

Uh, once my mom left, he [father] kind of went into like a deep depression, and then he's a severe alcoholic now ... he'd come off the truck and working on a in-town job, and it was a every night thing. And he went to the bars. I was still paying the stuff 'cause he was spending all his money to drink ... No money for food, no money for lights or anything 'cause he was usin' it all for alcohol. 
With her family facing poverty as a result of her father's alcoholism, this young woman quit high school to support herself and her younger sister through full-time, low-wage work. Although she reports feeling immense satisfaction in seeing her sister graduate from high school, she herself did not graduate or earn a GED.

\section{Developmental Salience of Childhood Domestic Violence}

Most of the women in the study describe how domestic violence, in tandem with parental substance abuse, resulted in home life characterized by financial instability, emotional chaos, and other sources of psychosocial risk. The data do not permit examination of a direct causal relationship between domestic abuse and particular developmental outcomes among the participants. Nevertheless, the women report strikingly similar patterns of familial circumstances, including childhood domestic abuse, and subsequent engagement in high-risk behaviors, such as dropping out of school, early sexual debut and unprotected sexual activity, use of drugs and alcohol, and leaving home at a young age, that are highly consistent with findings of other research (Anda et al., 2006; Arias, 2004; Bereczkei \& Csanaky, 2001). These adolescent "problem behaviors" (Jessor \& Jessor, 1977) are features of life pathways characterized by conduct disorders and status offenses among young women who have survived harsh environments such as those experienced by most of this study's participants (ChesneyLind, 1989; Ferguson \& Woodward, 2000). No single characteristic or experience, or one type of problem behavior, determined the women's adult status; rather, the impact of their actions combined or "stacked" over time, cumulatively creating ever greater difficulty in achieving financial, social, and physical security for themselves and subsequently their children. Below we identify more specifically what the women perceive as the most salient of their experiences and how these experiences affected their actions as they entered early adulthood.

\section{High-Risk Problem Behaviors}

Abusive and otherwise unhappy family lives contributed in many and complex ways to the young women engaging in a variety of high-risk problem behaviors, including detaching from and eventually dropping out of school. A few women took on adult responsibilities at a young age that made educational achievement difficult. One participant's mother suffered from severe emotional as well as physical illness:

My mom started getting real sick and kept me home a couple of days [a week] just to be with her...

A common experience is exemplified by another participant who, after her mother left her abusive husband, shuffled between her parents in two different cities before settling with her father, who lived in a poor school district. She attended school sporadically and eventually dropped out because "There wasn't one teacher in the whole building. It was bad." 
An aversive family environment led many women away from home beginning in early adolescence. Several participants began working part-time while in high school as a way to stay away from their families and gain financial independence. Sometimes long hours at work interfered with their sleep and schoolwork. However, when work became a distraction from school, in each instance it occurred within the context of family problems and an already increasing detachment from school.

Although the specific circumstances of dropping out of school vary among participants, typically they began to disengage from school in both attendance and work habits by the end of middle school. Although several participants reported that they were good students early in their education, most described themselves as teenagers who were "wild," "black sheep," and "always in trouble" at school. The majority of women spent a great deal of time with friends, universally characterized by themselves in retrospect as the "wrong crowd." With these peers the young women engaged in a variety of risky behaviors: They drank alcohol, used drugs, skipped school, and became sexually active.

I was so wild when I was a teenager, from the time I was 13 to the time I was about 16. I was very promiscuous. I would drink, smoke pot . . . and then I got pregnant with my daughter...

Some women were painfully explicit about how family abuse contributed to a complex of high-risk behavior and troubled outcomes. The woman who began staying out of school to keep her sick mother company explained why she first had sexual intercourse - unprotected — with the father of her baby at age 14 :

Due to what was going on with my father, I didn't want to have my virginity taken by my father so I slept with [son's father] instead . . . I do remember thinking I didn't want my dad to be the first person. I didn't want to have sex, but that was something I was thinking about.

The combination of previously missed days, morning sickness from the pregnancy that resulted from this liaison, and feelings of "confusion" led the young woman to drop out in 10th grade. She then left her parent's house to follow an older man to another state and began several years of drug use and involvement with a variety of abusive men that nearly caused her son to be removed by child protective services. While her history of incest was uncommon, the rest of her story contains elements reported by most of the other participants.

\section{Problems of Mental Health and Substance Abuse}

The majority of participants have been under psychiatric care and have taken medication for some form of anxiety and/or depressive disorder. One woman, whose child's father was violent toward her, suffers from emotional as well as undiagnosed physical problems that make it difficult to work steadily and that she attributes to being sexually abused by her father: 
Truly, what I've been going through, because you know, whenever I didn't know what the heck was wrong with me, you know, um, being so weak and, you know, really not being able to get up and everything. They couldn't tell that, you know, that it was my nerves, and that's the reason I'm out [of work].

Another young woman, who had five children between the ages 15 and 21, described her abusive father's impact on her own way of parenting and current emotional wellbeing as well as her capacity to hold a job:

I get all his bad traits from him, and I'm very controlling . . . That's bad-I try to break myself of it, but I have to be in control of everything that goes on or I get really upset. As far as-I have really bad nerves. I have panic attacks.

Several women reported problems with drugs and alcohol use beginning in adolescence. The woman whose mother was a heroin addict began using drugs herself after she "fled" home early to escape her uncle's sexual molestation. Another young woman who left her adoptive parents' emotionally hostile home at age 15 became deeply involved in drugs and alcohol with a series of substance-abusing men - one of whom, though she is not sure which, is the father of her older son. She lost more than one job because of her alcohol use.

\section{Domestic Abuse in Adult Relationships}

Consistent with known risks associated with children witnessing and experiencing domestic abuse, $78 \%$ of the women in this study became involved as adults in abusive relationships with men. Some experienced only one relationship with a violent husband or boyfriend; others have engaged in serial abusive relationships.

One woman was both a witness to and a victim of years of family violence. She, like several other participants, made the decision to leave home as an adolescent. She chose to "get out" in the most direct way she knew, through marriage:

I met a young man. My dad was really abusive. And this young man was my way out. So I got married at 16 years old ... I thought he was my ticket out. So I quit school. I gave up my dreams, I gave it all up.

Unfortunately, her ability to regain what she gave up in the way of her dreams was diminished even further by choosing a husband who was himself a drug abuser and violent toward her as her father had been. She "had a child at 17 [who died], 18, and 19 ," and then, "I made an attempt to go back to school. And my ex-husband made me quit. He said it wasn't his place to sit home with the children." It took 8 years, after leaving her ex-husband, of working at numerous part-time low-wage jobs, while taking care of her two children, one of whom has Turrette's Syndrome and the other severe attention deficit hyperactivity disorder (ADHD), to complete her GED at the age of 29.

Another woman says of her father's sexual abuse: 
My dad, I don't have anything to do with him. I mean I haven't been because he did things when I was a child that he should not have done to me. I may have to stop [talking] because when I get upset I have to throw up . . .

She left high school in 11 th grade, but at age 19 obtained a GED. She married soon after and quickly discovered that her husband was physically abusive:

It got to the point of there were more episodes of name calling, hitting, fighting, pushing, you know. Fractured this wrist. He was arrested I think a total of four or five times ... I got pregnant on my honeymoon.

After divorcing her husband, she worked at a minimum-wage job, but was not able to support herself and her son adequately. Soon after meeting a man who managed an apartment complex, they moved in together. She is brutally honest about her motivation for this decision, despite knowing the risk:

He moved me in. I was working and I moved in and I saw from that day, that second, he was an abuser ... So I let the alimony stop and everything and me and M. ended up getting married in daggone 3 months . . . Because I was scared. I knew he got a free apartment there because that come part of his package. He made good pay and a car and I was to the point that I was fixing to have to just go stay in a shelter and that's the last thing I wanted to do was have to go to a shelter with [my son].

Finally, one participant who is filing for divorce from her extremely abusive husband has no marketable skills, no income, and no immediate prospects for how she will support her child:

I am currently living with a friend, um, I'm not working ... I went to DSS [Department of Social Services], I'm waiting on assistance from them, um, I'm trying to get my son in day care through the ABC program, but I'm going to have to look for a job before I can do that. I did receive Medicaid probably about 3 days ago . . . My husband goes to court Thursday. He lost his job, and he's losing his house, which is our house. And um he's probably going to go to jail ... so I'm not receiving child support and I don't really have anywhere to live, and I don't have much as far as housing goes, the waiting list is a year.

This young woman places her current situation in a perspective that is linked to having been sexually abused by her stepfather, who terrorized her mother and half sister:

At 12 years old I ran away because of him, and my mother did not believe me and she stayed with him for four years after. But once I said something she didn't believe me because the girls that I was hanging out with at school and all she considered them a bad crowd and she thought they put me up to it. My friend's mother called social services out to my house. And I went and lived with my father for about 3 months and then I got kicked out of school and my mother made me come back. And I just kind of went into a rebellion thing basically, probably at the age of 14 and I went to a drug rehabilitation center, I got involved in drugs and alcohol. 
She dropped out of school soon after. Recounting her subsequent marriage to an abusive man, she wonders of it is a pattern:

I think I'm following in my mother's footsteps . . Because I don't know—it's just—it's complicated. He was extremely abusive, alcoholic, drugs, the ranting and raving, the temper. He reminds me so much of my stepfather now it's pitiful. The first time he ever hit me was the day we got married. The day we got married after everyone left and we were getting ready to go to bed and everything he just looked at me straight in my eye. He says, "We're married now, you're mine, you'll do what I want you to do."

Possessing minimal education and skills, in combination with mental health problems she attributes to the stress from abuse, she perceives few options and feels deep frustration:

And I always wanted to go back to school but it just seems like, well, I've got to worry about money. And everybody asks me, "Well are you gonna go back to school?" and I say "How am I gonna go back to school? I've got bills to pay. You know I can't afford to go back to school." And it's like-I just, I can't eat. I can't do anything. And it's like my nerves are driving me crazy here lately. I'm just—I'm constantly analyzing everything and it's just things aren't the way I want them. This isn't what I want.

\section{Discussion}

The Southern, poor, White, single mothers interviewed in the study consistently reported domestic abuse in their families of origin and later in their own relationships with men. The salience of this abuse is evident in their descriptions of how abuse contributed to many of their decisions at various points leading to their currently disadvantaged circumstances. Specifically, many of the women left home early to escape negative family environments, dropped out of school, engaged in high-risk behavior that sometimes resulted in teen pregnancy and involvement in abusive relationships.

These early problems diminished their abilities to accumulate assets in a variety of ways. Beginning in childhood, some of these participants had mothers who were isolated and prevented from working by abusive husbands. These restrictions deprived the women of opportunities to succeed in the job market or contribute to the family income. Thus, the supportive family relationships that are an essential form of social capital were compromised by the violence and chaos at home. Participants whose parents divorced had less access to mothers' and fathers' time and financial resources. When families were intact, the negative emotional climate often diminished the young women's capacities to perform well in school or develop personal characteristics leading to occupational success.

One of the consequences of early flight from their families of origin, teen pregnancy, substance abuse, and other problem behaviors is that the participants attained low levels of human capital, such as education and marketable job skills. Environmental factors such as living in rural areas, community poverty, limited social services, and 
limited job opportunities compounded the negative impact of individual experiences. Recent changes in the conditions of public assistance due to welfare reform exacerbate the dire economic straits these women face.

Findings from this small study do not provide the kind of evidence necessary to resolve the important theoretical debates on the relative significance of life course adversity, personality traits, and evolutionary models that explain how adverse childhood circumstances, such as domestic violence, create life pathways characterized by adult domestic violence, poverty, and mental health problems (Anda et al., 2006; Ferguson \& Woodward, 2000). Nevertheless, these women's experiences are highly consistent with other research that reveals the cumulative impact of exposure to stressors in childhood homes wracked by poverty and domestic abuse- the consequences for adult functioning when young women are focused on surviving emotional and physical adversity rather than investing in their capacity to flourish in school and work as adults. The abuse described here is one of many identified experiences and characteristics that accumulated over the life course and contributed to the negative multifarious outcomes. We refer to the accumulation as a form of "stacking" of vulnerabilities (see Figure 1). Such stacking appears over time to reduce the women's abilities to develop human and social capital and accumulate assets.

One of the major contributions of this study is the focus on the "cultural-structural nexus" (Rochelle, 1997) among poor, White, Southern, and rural women. Neither a cultural pathological perspective nor a purely structural perspective fully captures the dynamic and complex lives of these women in poverty. Through our research using life histories, we are able to provide in-depth information that captures some of this complexity. Furthermore, our research also adds to knowledge of how both human and social capital become compromised over the life course, contributing to the inability of the participants to obtain assets and the positive features that accompany them. In this article, we have identified domestic abuse during both childhood and adulthood as a particularly salient negative influence that compromises the participants' ability to achieve economic self-sufficiency.

\section{Implications}

Several policy and programmatic implications follow from the findings reported. As Sherraden (1991) argued, if policies can assist parents in obtaining assets, then they are better able to break a cycle of economic deprivation that often continues from one generation to the next. The potential importance of this investment to poor women who experience domestic violence and may be ill-equipped to participate fully in the labor market and become self-sufficient is evident in the life histories reported here. The narrowing of the definition of "work" under welfare reform has made it even more difficult for women to obtain higher levels of education, thus further limiting their capacity to develop human capital.

In addition, it is critical that policies be more responsive to the specific circumstances of poor women who experience abuse. For example, given the greater vulnerability of poor women to domestic abuse, it is important to further examine the efficacy 


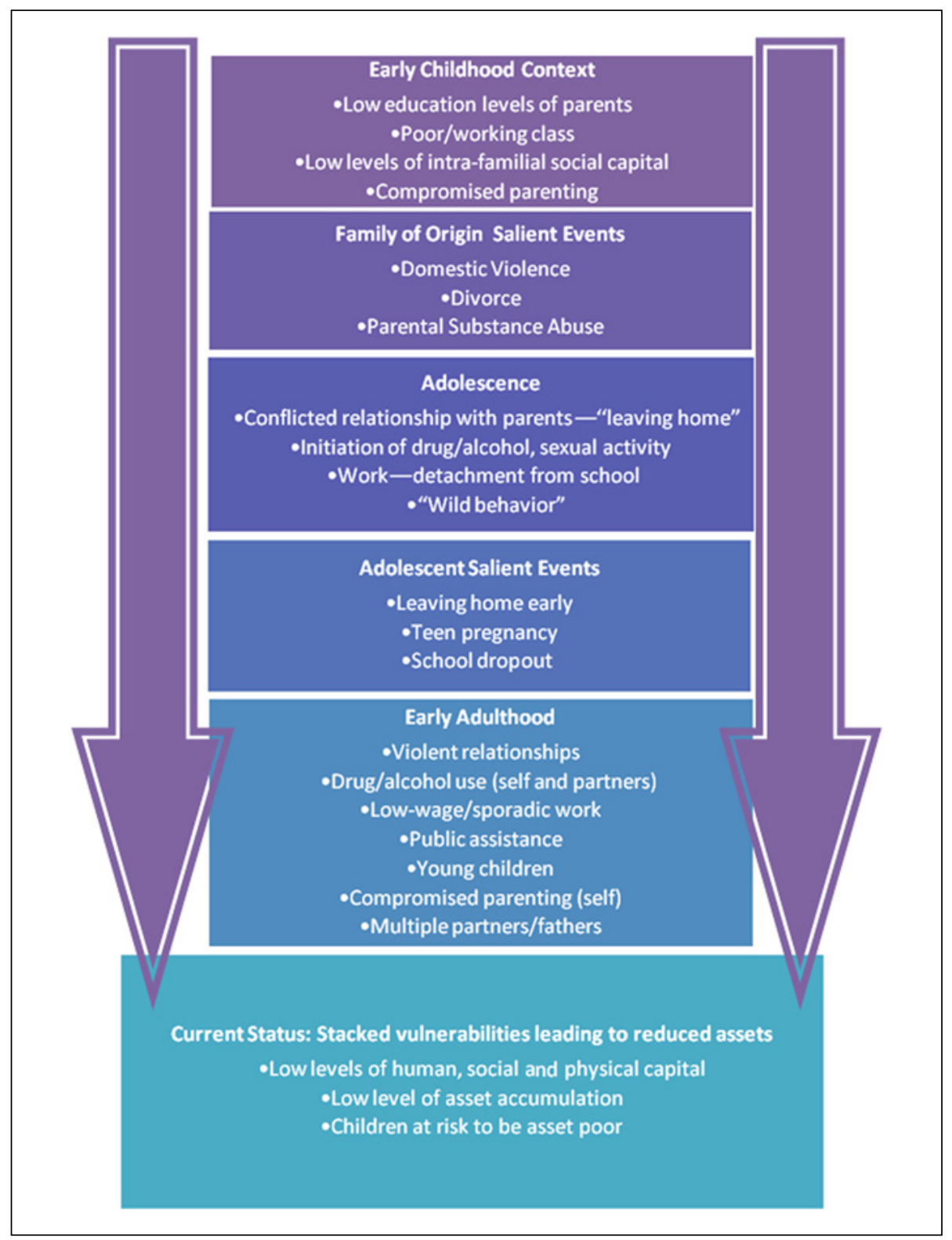

Figure I. Stacked vulnerabilities: Developmental trajectory of risks to asset accumulation.

of the Family Violence Option that is part of TANF to protect these women and their children who are at risk. Many states currently have or are considering policies that automatically link child abuse with domestic violence. However, given what we know 
about the dynamics of domestic violence in the lives of poor women, policies should encourage greater caution in using child protective service interventions automatically in situations of domestic violence. Instead, services should be geared to help women safely remove themselves and their children from violence.

A growing body of evidence finds that health and mental health consequences of ACEs throughout the life span can be a significant barrier to optimum adult health and functioning. The majority of the women in this study experienced several of the characteristic "adverse childhood events," including recurrent physical and emotional abuse, neglect, witnessing domestic violence, household members with substance abuse problems, and sexual abuse. In compelling life course narratives, the health and mental health consequences of violence throughout the lives of the women in this study are revealed as salient to their developmental trajectories. The violence presents across a developmental spectrum, placing the girl, adolescent, and then young woman at increased risk over the life span. The salience of this exposure to violence at multiple time points should not be understood only as disparate events, but rather as having a cumulative impact in the lives of these women. Consistent with this perspective, earlier screening and both primary and secondary prevention are warranted. Screening in diverse health and mental health settings for adverse events during childhood could have significant benefits for women and their children. Findings from this study reveal the potential benefits of early intervention beyond the important overall goal of reducing child abuse. Early intervention may not only reduce child abuse but also interrupt a dangerous trajectory to premature death, poor health, and mental health problems among adult women - all of which are related to the accumulation of human capital and asset accumulation across the individual life span and generations. Screening in medical settings, such as community health, obstetrical, and family medicine clinics, could help identify women with significant histories of violence, and targeted interventions could be used to reduce risk for women and their children (MacMillan et al., 2009). Creating specialized interventions that address both current and past experiences of abuse, what some refer to as trauma informed care, could improve outcomes for women who experience both current and past violence (Jasinski, 2004; Seng, Sperlich, \& Low, 2008). Certainly such intervention requires moving beyond the medical model of health to a model recognizing the social determinants of health and mental health and that offers realistic intervention that targets the vulnerabilities of at-risk populations.

In conclusion, this study highlights the salience of domestic violence both in the early and current lives of poor, White single mothers living in the rural South. We demonstrate the ways in which these experiences of violence contribute to reduced human and social capital. Their reduced assets leave them, and their children, economically, socially, physically, and psychologically vulnerable to continued poverty and violence. However, early screening and intervention may result in the reduction of negative outcomes. With the promise of health care reform, the possibility of increased access for at-risk women and children to health care settings may result in a greater number of women who could be screened for risk and offered intervention and services that reduce the risk for violence and poor health outcomes. 


\section{Declaration of Conflicting Interests}

The author(s) declared no potential conflicts of interest with respect to the research, authorship, and/or publication of this article.

\section{Funding}

The author(s) disclosed receipt of the following financial support for the research, authorship, and/or publication of this article: This work was funded in part by the Lois and Samuel Silberman Fund, New York Community Trust.

\section{References}

American Psychological Association. (1996). Violence and the family. Washington, DC: Author. Anda, R. F., Felitti, V. J., Bremner, J. D., Walker, J. D., Whitfield, C., Perry, B. D., et al. (2006). The enduring effects of abuse and related adverse experiences in childhood. European Archives of Psychiatry \& Clinical Neuroscience, 256, 174-186.

Annie E. Casey Foundation. (2009). Children at risk: State trends 2009. Retrieved from http:// www.aecf.org/kidscount

Arias, I. (2004). The legacy of child maltreatment: Long-term health consequences for women. Journal of Women's Health, 13, 468-473.

Bell, H. (2003). Cycles within cycles. Violence Against Women, 9, 1245-1262.

Bereczkei, T., \& Csanaky, A. (2001). Stressful family environment, mortality, and child socialization: Life history strategies among adolescents and adults from unfavorable social circumstances. International Journal of Behavioral Development, 25, 501-508.

Bradbury, C., \& McManus, R. (2007, November). Criminal domestic violence (CDV) in South Carolina: An examination of the effects of ACT 166 of 2005 (A Report to the South Carolina Office of Research and Statistics of the Budget and Control Board to the Department of Public Safety).Retrieved from http://www.scdps.gov/ojp/stats/DomesticViolence/ Criminal\%20Domestic\%20ViolenceREPORT.doc

Browne, A., Salomon, A., \& Bassuk, S. (1999). The impact of recent partner violence on poor women's capacity to maintain work. Violence Against Women, 5, 393-426.

Carlson, B. (1984). Children's observations of interparental violence. In A. Edwards (Ed.), Battered women and their families (pp. 147-167). New York: Springer.

Chamberlain, L. (2002, January-February). Domestic violence: A primary care issue for rural women (The Network News). Washington, DC: National Women's Health Network. Available from http://www.womenshealthnetwork.org

Chesney-Lind, M. (1989). Girls' crime and women's place: Toward a feminist model of female delinquency. Crime \& Delinquency, 35, 5-29.

Coleman, J. (1990). Foundations of social theory. Cambridge, MA: Harvard University Press.

Cook, P., \& Dagata, E. (1997). Welfare reform legislation poses opportunities and challenges for rural Americans. Rural Conditions and Trends, 8(2), 35-39.

Curcio, C. (1997). The Passaic County Study of AFDC recipients in a welfare to work program. Passaic County, NJ: Passaic County Board of Social Services.

Danziger, S. K., Kalil, A., \& Anderson, N. J. (2000). Human capital, physical health, and mental health of welfare recipients: Co-occurrence and correlates. Journal of Social Issues, 56, 635-654.

Eby, K. (2004). Exploring the stressors of low-income women with abusive partners: Understanding their needs and developing effective community responses. Journal of Family Violence, 19, 221-232. 
Economic Research Service, U.S. Department of Agriculture. (1998). Rural conditions and trends. Washington, DC: Author.

Edelson, J. (1999). The overlap between child maltreatment and women battering. Violence Against Women, 5, 134-154.

England, P., \& Edin, K. (2007). Unmarried couples with children. New York: Russell Sage Foundation.

Child Welfare Information Gateway. (2013). Child witnesses to domestic violence. Washington, DC: U.S. Department of Health and Human Services, Children's Bureau.

Durborow, N., Lizdas, K., Flaherty, A., \& Marjavi, A. (2013). Compendium of State and U.S $>$ erritory Statues and Policies on Domestic Violence and Health Care. Futures without Violence. Retrieved from http://www.futureswithoutviolence.org/content/features/ detail/1584/

Ferguson, D., \& Woodward, L. (2000). Educational, psychosocial, and sexual outcomes of girls with conduct problems in early adolescence. Journal of Child Psychology and Psychiatry, 41, 779-792.

Findeis, J. (1995). Gender differences in human capital in rural America. In J. Beaulieu \& D. Mulkey (Eds.), Investing in people: The human capital needs of rural America. (pp 183212). Boulder, CO: Westview Press.

Findeis, J., \& Jensen, L. (1998). Employment opportunities in rural areas: Implications for poverty in a changing policy environment. American Journal of Agricultural Economics, 80, 1000-1007.

Gortner, E., Gollan, J., \& Jacobson, N. (1997). Psychological aspects of perpetrators of domestic violence and their relationships with the victims. Psychiatry Clinics of North America, $20,337-352$.

Hotaling, G. T., \& Sugarman, D. B. (1986). An analysis of risk markers in husband to wife violence: The current state of knowledge. Violence and Victims, 1, 101-124.

Jasinski, J. (2004). Pregnancy and domestic violence: A review of the literature. Trauma, Violence, \& Abuse, 5, 47-64.

Jessor, S., \& Jessor, R. (1977). Problem behavior and psychological development: A longitudinal study of youth. New York: Academic Press.

Johnson, R. (2000). Rural health response to domestic violence: Policy and practice issuesEmerging public policy issues and best practices [Federal Office of Rural Health Policy Order No. \#99-0545(P)]. Washington, DC.

Kendler, K. (2002). Childhood sexual abuse and adult psychiatric and substance use disorders in women: An epidemiological and co-twin control analysis. Archives of General Psychiatry, 57, 953-959.

Kimerling, R., Alvarez, J., Pavao, J., Mack, K., Smith, M., \& Baumrind, N. (2009). Unemployment among women: Examining the relationship of physical and psychological intimate partner violence and posttraumatic stress disorder. Journal of Interpersonal Violence, 24, 450-463.

Lyon, E. (2000). Welfare poverty and abused women: New research and its implications. Harrisburg, PA: National Resource Center on Domestic Violence.

MacMillan, H., Wathen, C., Jamieson, E., Boyle, M., Shannon, H., Ford-Gilboe, M., et al. (2009). Screening for intimate partner violence in health care settings: A randomized trial. Journal of the American Medical Association, 302, 493-501.

McManus, R. (2006). Nowhere to run, nowhere to hide: a profile of domestic violence in South Carolina. South Carolina Department of Public Safety. http://dc.statelibrary.sc.gov/handle/10827/9362 
Mihalic, S. W., \& Elliott, D. (1997). A social learning theory model of marital violence. Journal of Family Violence, 12, 21-47.

Myers, J. E., \& Gill, C. (2004). Poor, rural and female: Under-studied, more at-risk. Journal of Mental Health Counseling, 26, 225-242.

Nord, M. (1999). Rural poverty rate unchanged. Rural Conditions and Trends, 9(2), 81-84.

Office for the Prevention of Domestic Violence. (1998). Model domestic policy for counties. Retrieved from http://www.opdv.ny.gov/professionals/coordination/model_policy/index. html

Osborne, C. (2002). Diversity among unmarried parents: The importance of marriage expectations. Princeton, NJ: Center for Research on Child Wellbeing, Office of Population Research, Princeton University.

Peled, E., Jaffe, P., \& Edelson, J. (Eds.). (1995). Ending the cycle of violence: Community responses to children of battered women. Thousand Oaks, CA: SAGE.

Raphael, J., \& Tolman, R. (1997). Trapped by poverty, trapped by abuse: New evidence documenting the relationship between domestic violence and welfare. Chicago, IL: Taylor Institute and the University of Michigan.

Riger, S., \& Staggs, S. (2004). Welfare reform, domestic violence, and employment. Violence Against Women, 19, 961-990.

Rochelle, A. (1997). No more kin: Exploring race, class and gender in family networks. Thousand Oaks, CA: SAGE.

Romans, S., Poore, M., \& Martin, J. (2000). The perpetrators of domestic violence. Medical Journal of America, 173, 484-488.

Rural Poverty Research Institute. (1999). Rural Americans and welfare reform: An overview assessment. Retrieved from http://www.rupri.org/Forms/p99-3.PDF.

Saunders-Medlock, Lisabeth (2003). Getting Away with Murder: A Report on Domestic Violence in South Carolina, SCCADVASA. Columbia South Carolina. Retieved from http://www.allianceforwomen.net/public/files/docs/scdomesticviolencereport.pdf

Schechter, S. (2000). Expanding solutions for domestic violence and poverty: What battered women with abused children need from their advocates (Building comprehensive solutions to domestic violence: Publication \#13, A Vision Paper). Retrieved from http://snow. vawnet.org/Assoc_Files_VAWnet/BCS13_ES.pdf

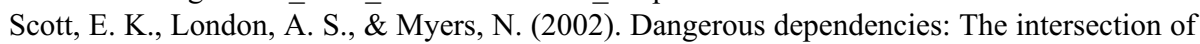 welfare, reform and domestic violence. Gender \& Society, 16, 878-897.

Seng, J., Sperlich, M., \& Low, L. (2008). Mental health, demographic, and risk behavior profiles of pregnant survivors of childhood and adult abuse. Journal of Midwifery \& Women's Health, 4, 511-521.

Sherraden, M. (1991). Assets and the poor: A new American welfare policy. Armonk, NY: M. E. Sharpe.

Smith, M. W. (2001). Abuse and work among poor women: Evidence from Washington state. In S. W. Polachek (Ed.), Worker well-being in a changing labor market (Research in Labor Economics, Vol. 20, pp. 67-102). Bingley, UK: Emerald.

South Carolina Coalition Against Domestic Violence ans Sexual Assualt, n.d.). Domesitic Violence Facts. Retrieved from http://www.sccadvasa.org/resources/information/domestic-violence-facts/

Southern Rural Development Center. (2003). Children and poverty in the rural south (SDRC Policy Series, November, No. 2). Mississippi, State: M: Author.

Spaccarelli, S., Caotsworth, J., \& Bowden, B. (1995). Exposure to serious family violence among incarcerated boys: Its association with violent offending and potential mediating variables. Violence and Victims, 10, 63-182. 
Stacy, W., \& Shupe, A. (1993). The family secret. Boston, MA: Beacon Press.

Straus, M., \& Gelles, R. (1990). Physical violence in American families. New Brunswick, NJ: Transaction Publishers.

Teitler, J., \& Reichman, N. (2001). Cohabitation: An elusive concept. Princeton, NJ: Center for Research on Child Wellbeing, Princeton University.

Tolman, R., \& Rosen, D. (2001). Domestic violence in the lives of women receiving welfare. Violence Against Women, 7, 141-158.

Violence Policy Cneter (2013). When Men Murder Women: An Analysis of 2011 Homicide Data. Violence Policy Center, Washingon DC.Retrieved from http:/www.vpc.org/studies/ wmmw2013.pdf

Vogel, L., \& Marshall, L. (2001). PTSD symptoms and partner abuse: Low income women at risk. Journal of Traumatic Stress, 14, 659-684.

Vogel, W., \& Coward, R. (1995). The influence of health and health care on rural economic development. In J. Beaulieu \& D. Mulkey (Eds.), Investing in people: The human capital needs of rural America (pp. 285-313). Boulder, CO: Westview Press.

Yadama, G. N., \& Sherraden, M. (1996). Effects of assets on attitudes and behaviors: Advance test of social policy proposal. Social Work Research, 20(1), 3-12.

\section{Author Biographies}

Naomi Farber is an associate professor of social work at the University of South Carolina. She earned her MSW at the University of Michigan and her $\mathrm{PhD}$ from the University of Chicago School of Social Service Administration. Her scholarship has focused on family formation in the context of urban and rural poverty, and adolescent pregnancy and parenting. She is the author of Adolescent Pregnancy: Policy and Prevention Services.

Julie E. Miller-Cribbs is an professor and director of the Anne and Henry Zarrow School of Social Work at University of Oklahoma.. She has a bachelor's degree in psychology from Colorado College, a master's degree in social work from the University of Chicago, and received her PhD from Washington University George Warren Brown School of Social Work. Her research interests include urban and rural poverty, welfare reform, health care disparities, and the use of social and human capital by individuals in poverty. Her work appears in scholarly journals, textbooks, and course outlines related to cultural diversity. She is the author of three books. 